\title{
The Design Method of Cultural Relics Park from the Point of View of Planning
}

\author{
Zhijin Zhao \\ Yunnan University of Business and Management \\ Kunming, China 650106
}

\author{
Lijun Shi \\ Yunnan University of Business and Management \\ Kunming, China 650106
}

\begin{abstract}
Cultural sites are visible and intangible traces left over from ancient times. To a nation, culture is the root of the spirit. For a city, culture is the source of vitality and soul. The charm and attractiveness of a city depend mainly on its unique culture. This paper analyzes and studies the environmental form of Cultural Heritage Park. We explore ways to exploit and utilize cultural sites. It is believed that the comprehensive protection, excavation and utilization of cultural sites can not only achieve the protection and reuse of cultural resources, but also be mutually beneficial with the quality of the city's landscape and ecology, so as to achieve the overall improvement of the city's humanities, landscape and ecological environment. The way to excavate the cultural connotation of the city not only meets the people's pursuit of culture, but also promotes the development of the urban ecological landscape, it has a virtuous cycle through the industrial way in the economy. At present, the excavation and protection of the site resources are still at the initial stage, and the relevant concepts, policies and regulations are in the initial stage of development. There are many contradictions in the theories and methods of planning and designing of the ruins park. This paper analyzes these problems and tries to find out an effective way.
\end{abstract}

Keywords-cultural relics park; planning and design; methods

\section{INTRODUCTION}

Cultural Heritage Park is still a new type of park in China. Its purpose is to protect and utilize the site culture, thus affecting the development of the city. Because of its particularity, the construction of this park shows various contradictions and problems in the early stage, which is also an inevitable alternative in urban development. The methods and means adopted in the planning and design of ruins and parks will bring benefits and impacts to the site culture. This is the direction of this article. In order to make better protection and utilization of the excavated sites, it is necessary to study the objective existence and planning of the site park, which is of great significance in the real society.

\section{COnSERVATION Status of Chinese Sites}

China is at the primary stage in the study of ruins park, and the development and utilization of ruins are not yet mature. The site park is a comprehensive complex and diverse landscape. Its internal factors and contents are extremely extensive. It must be tortuous to explore a correct road for construction and development.

The protection and development of the site started late in China. After the founding of new China, the national key cultural relics protection units have been published one after another. The government has paid more and more attention to the cultural heritage. It provides a reliable guarantee for the development of the ruins park. At the same time, it strengthens the investment of cultural heritage and makes the site park develop rapidly. In the upsurge of excavation and development of cultural heritage, protection must be carried out according to procedures. All procedures should comply with relevant legal and professional rules, and the opinions of the relevant parties must be widely solicited. Among them, the evaluation of the value of cultural relics should be placed first.

Yu Kongjian ${ }^{1}$ pointed out that the construction of the Yuan Dadu ruins park should start with site conservation, ecological construction and recreation. The Ming City Wall Ruins Park is designed to protect the city wall sites, and the atmosphere and space made up of the Ming Dynasty walls are limited, and the style of the city wall of the Ming Dynasty is truly reproduced. In the design of Yongning ancient Wei Ruins Park, Sun Fengqi ${ }^{2}$ proposed that we should respect and understand the historical context. Tang Liping and $\mathrm{Ni}$ Yinan ${ }^{3}$ once said that we should develop appropriately on the basis of understanding, and try to preserve historical traces. However, it is not necessary to use antique buildings at the same time. Because its park has become a part of the city landscape and even the daily life of the people, the thoughts of the ruins park have brought infinite space. It is like a bridge that adheres to history and modernity. It also provides people with spiritual and material wealth.

Yu Kongjian: Professor of urban and regional planning of Peking University, a part-time professor of landscape design and urban planning in Harvard University, Dean of the school of landscape and architecture of Peking University, chief designer of the Institute of landscape and architecture planning and design in Beijing.

Sun Fengqi: Professor of Architecture Department of Tsinghua University, director of Landscape Architecture Research Institute, Institute of architecture.

Dr. Tang Liping: Ph.D., School of architecture and urban planning, Tongji University. Ni Yinan: Director of Landscape Department, national historical and cultural city research center, Tongji University, senior engineer. 


\section{ThE PRODUCTION OF PARK AND SITE PARK}

The first park in China is the concession Park in Shanghai. At that time, it was called the "public garden" in the declaration, which was originally translated as a concession park. It was not until 1903 that the Chinese students who studied in Japan introduced the Japanese Park in the "Zhejiang tide". In the second year, the Dagong newspaper used the word park when it was reported that the park was built in Nanjing, and the park was gradually replaced by the public garden and became a proper noun. The first park in China was the "public garden" with a western style garden style which was built in Shanghai in 1868 , but it was angry with a paper "the Chinese and the dogs are not allowed in". It was not until the implementation of the Huayang sub park plan in 1890 that there was a park belonging to Chinese people. In early 1880 s, some private gardens were gradually open to the public, such as Shen Yuan, Zhang Yuan, Xu Yuan, Yu Yuan, etc.

At the beginning of the emergence of the park, the park emphasizes its public openness, which is mainly to provide services for the public. It also relieves the pressure on urban development and balances the role of the urban ecosystem. It is very important in the process of modern urban development. ${ }^{4}$

\section{ClassificAtion OF Site TyPES}

According to the function and content difference of the site, the site park is divided into architectural site park, city site park, garden site park, Mausoleum site park, event type site park and active site park. There are no cases of water conservancy sites. In the design of ruins park, it will cause damage to riparian and ecology. Therefore, this article will not discuss.

- Architectural site park: the main landscape is the site park type of the building mono site. The site includes the mono site of the sacrificial building, the monarch palace site, the city gate, the city wall and other artificial building sites, such as the Xingqing palace in Xi'an.

- The city site park: the city pattern display and the city culture as the main content of the site park, the site is an important component of the urban pattern, such as the Zhao Wangcheng site park in Handan.

- Garden Ruins Park: the main landscape is to display the historical garden style, such as the Old Summer Palace Ruins Park in Beijing.

- Mausoleum site park: the main site is a mausoleum or burial group of ancient emperors or historic figures, such as the Mausoleum of the First Qin Emperor site park in Xi'an.

\footnotetext{
$4 \quad$ Xie Weili: the research on the contradictions and Countermeasures of the protection and development of the present site park - Taking the Huaqing Palace Site Park as an example, Beijing Forestry University, June 2008, 7-9
}

- Event type Ruins Park: the main landscape is the place where historical events happen, such as Tangshan earthquake ruins park.

- Activity type Ruins Park: the main landscape is an ancient place of historical activity, and reflects a special historical activity of mankind ${ }^{5}$.

\section{THE PRINCIPLE OF AUTHENTICITY AND INTEGRITY}

The authenticity of the site is a basic factor recognized internationally for the protection, assessment and monitoring of cultural heritage. It is true, original, faithful and sacred, but not false, duplicating, forgery and blasphemy. ${ }^{6}$ Keeping the authenticity of the site is a guideline that must be observed in the planning and design of the ruins park. The authenticity of the site includes site structure, shape, historical context, style design, construction materials and technology. The authenticity of the site is the embodiment of the value of its own ruins. If it is lost, it will not have the value of protection.

The integrity of the site is the original state that has not been exploited, and the natural heritage is evaluated by the original state of the site. Its integrity includes regional natural environment and social culture, but itself is also a whole, the regional environment and the natural environment constitute the whole ecological system, and the natural environment and social culture also have a close relationship. These environmental factors and elements have inherent rationality for existence and development. From the perspective of the development of site preservation, the integrity of sites has been increasingly emphasized. In the planning of the site park on the basis of adhering to the principle of integrity, we should take a comprehensive consideration of the site and protect the elements of historical information in a comprehensive way, which cannot be omitted. Not only to protect the great environment of the site, but also to protect the body of the site; not only to protect the human environment of history, culture and emotion, but also to the protection of the material environment ?

\section{THE PRINCIPLE OF REGIONAL AND CULTURAL CONNOTATIONS}

Urban landscape design should give full consideration to the characteristics of regional natural and cultural landscapes, respecting the natural geographical conditions and social and cultural backgrounds of the region. Use the natural geographical landmark of the region, the continuation of

5 Xie Weili: the research on the contradictions and Countermeasures of the protection and development of the present site park - Taking the Huaqing Palace Site Park as an example, Beijing Forestry University, June 2008, 7-9

6 Xu Songling Zhang Xiaoming Zhang Jiangang: 《the protection and management of cultural heritage - China's practice and the development of theory》, social science literature press, March 2003, 7691

He Guanglei "Research on the theory and method of planning and design of ruins park", Xi'an University of Architecture and Technology, May 2010, 47-48. 
regional context and local folklore to enhance regional characteristics. The planning and design of site gardens should absorb various cultural traces left behind in the regional culture, which is highly identifiable. It represents a regional symbol with distinct characteristics, and it often gives a strong impression.

In modern times, cities tend to be the same, and urban characteristics are gradually weakening. Under the background of globalization, the integration of economy and culture has become more and more similar, resulting in the disappearance of regional characteristics driven by various aspects. At the same time, the new technology, new technology, new materials and new design ideas have accelerated the process of urbanization, while more and more traditional, cultural and diverse features of the landscape area have been lost. Different regions, time and space, history and culture endow it with different personalities and characteristics, and the convergence of culture is gradually weakening.

Heritage Park needs to reflect and inherit the cultural connotation of the site. In the planning and design, we should focus on the cultural information of the related times brought by the site, excavate the culture depth, and design the cultural similar landscape and project on the basis of it. We should create a distinctive cultural atmosphere and protect and utilize the sites. Conversely, such ruins park can also enhance the cultural connotation and urban characteristics of the city. The culture of each city is different, and once the culture becomes the style of the city, the city's face is not only the site itself, but also the continuity of the city's context and the historical memory of the city. Taking the Qujiang site park in Xi'an as an example, the construction of the site park is not only expressed as Qujiang culture, but also more important with the Tang Feng Garden to reflect the unique cultural atmosphere of the Xi'an city.

\section{PRoblems AND SUGgestions ON SUSTAINABLE DEVELOPMENT OF RUINS PARK}

\section{A. Problems and Suggestions on Information and Sustainable Development}

To a certain extent, the civilization of a country can be determined from the attitude towards culture. The more modern society, the more attention is paid to the sustainable development of cultural sites. Different forms and functions of cultural sites should be implemented in different ways to achieve sustainable development of site information.

The site has been shelved for hundreds of years or even thousands of years. Many of them have not existed, leaving only cultural relics or remnant building sites. There are also some burial sites which are deep underground for many years. Because of the limited scientific and technological level, we are afraid to excavate and show them. Therefore, we can only carry out the measures of backfilling and protection. Even after the test of the key areas, it can only show one part. Even if there are primeval objects, modern people cannot interpret ancient history. The ruins park must show this historical information to visitors. Then the missing information is filled, the information is too complex to be reflected in a simple form, and no conditions must be displayed. No matter whether it is filled, simplified or forced to display, it destroys the original content of the site, and has an impact on its protection and sustainability. The form of park land is also a reflection of preservation to some extent, because some of its underground areas have not been excavated, and this undisturbed park has been protected.

\section{B. Problems and Suggestions on Environmental Capacity and Short-term Benefits of the Site}

The site's capacity is limited in its specific historical period. Because of its high historical and cultural value, site park usually attracts a continuous stream of tourists to watch. The higher the historical and cultural value, the more tourists are. The excessive number of tourists will bring great pressure on the site, and the crowds of crowds in the golden period are more destructive to the ruins, and the destruction of the sites is difficult to predict if the relevant departments do not control the number of the sites. The protection of the ruins is based on the recognition of the masses and culture, and relies on the financial strength of the folk organizations to avoid the complete reliance on the government in financial affairs, and the policy of the site ancient sites promoted by the government is twice the result. We should strengthen the public participation level, listen to many opinions and take into consideration the various elements of the urban society's requirements for the site. We should establish perfect site legal procedures and strict censorship system, and carry out unified management and planning of the site space. All procedures for site environment need approval and permission. Because the government owns all the land rights of the site and the historical environment, we must strictly control the development and construction, and fundamentally avoid destroying the ruins due to urban development.

\section{CONCLUSION}

The ruins culture park is the contradiction between the site and the park. Before the planning and design of the site park, the contradictions should be analyzed and the protection is emphasized. Protection is the fundamental point of contradiction between ruins and parks. The application of ruins park is solved by solving the problem of site protection. The author believes that the historical elements and regional elements of the integration of modern display methods can effectively carry out the construction of the site on the basis of protection, not only to retain the memory of the city, but also to promote the industrial development of cultural sites.

Controlling the original appearance, atmosphere, information, environmental capacity and functional scale of the site, the site can be rationally planned. It can continue the cultural context and revive the trace of historical development.

The purpose of building cultural relics park with reasonable design techniques is to preserve the historical information, the site should be adapted to the new way of life, so that cultural sites and parks can be coordinated to ensure harmonious and sustainable development. 


\section{REFERENCES}

[1] Zhang Song. The International Charter for the Protection of Urban Cultural Heritage and Domestic Laws and Regulations [M]. Shanghai: Tongji University press, 2007.

[2] Li Lingfu. Urban Layout and Geographical Basis of Ancient Capital Xi'an [M] Beijing: People's Publishing House, 2009.

[3] Xu Songling, Zhang Xiaoming, Zhang Jiangang. Protection and Management of Cultural Heritage: Progress in China's Practice and Theory [M]. Beijing: Social Science Literature Press, 2003.

[4] Zhou Bing. Daming Palace - the Searing Grand Ruins [M]. Shaanxi: People's Publishing House, 2009.

[5] Zhang Jinqiu. Datang Furong Garden [M]. Beijing: China Architecture Industry Press, 2006.

[6] Ruan Yisan. On the Protection of Urban Heritage [M]. Shanghai: Shanghai Science and Technology Press, 2003.

[7] Chen Xiaotong. Inheritance, Integration and Evolution -- Research on the Development of American Landscape Architecture [M]. Nanjing: Southeast University press, 2005

[8] Wang Jun. City Records [M]. Beijing: Life, Reading, New Knowledge Triple Bookstore, 2003.

[9] Hei Chuan, Ji Zhang. Thoughts and Techniques of Urban Design [M]. Beijing: China Construction Industry Press, 2004.

[10] Chen Zhihua. International Documents on Conservation of Historical Buildings and Historical Sites [M]. Taipei: Boda Publishing Co., Ltd., 1993.

[11] Xiang Ma, Yi Lang, Zuo Gu, Shun Yan. Environmental Psychology [M]. Beijing: China Construction Industry Press, 1986.

[12] Chen Chongzhou. Say Garden [M]. Shanghai: Tongji University Press, 1984.

[13] Wang Fuchen. Form Integrity: Significance of Urban Design [M]. Beijing: China Construction Industry Press, 2006.

[14] Collection of Urban Planning and Design Institute of Xi'an Jian Da. Xi'an Jian Da Urban Planning and Design Institute, [M]. Beijing: China Architecture Industry Press, 2006 